\title{
Assessment of Knowledge Levels and Information Sources Related to Breast Diseases: A Prospective Questionnaire Survey
}

\author{
Safak Ozturk \\ Department of General Surgery, Faculty of Medicine, Izmir University, Izmir, Turkey \\ Email address: \\ surgeon0052@gmail.com \\ To cite this article: \\ Safak Ozturk. Assessment of Knowledge Levels and Information Sources Related to Breast Diseases: A Prospective Questionnaire Survey. \\ European Journal of Preventive Medicine. Vol. 7, No. 1, 2019, pp. 7-10. doi: 10.11648/j.ejpm.20190701.12
}

Received: December 18, 2018; Accepted: December 28, 2018; Published: February 15, 2019

\begin{abstract}
Introduction: We aimed to improve the chance of early diagnosis and curative treatment, to evaluate the level of knowledge about breast diseases and complaints, to increase the awareness and relationship between patients and surgeons, and to put forth the patient's expectations from surgeons because of the importance of breast cancer. Materials and Methods: 100 female patients, who were admitted to general surgery policlinic of Izmir University Faculty of Medicine between January 2016 to April 2016 with complaints of breast disease were studied prospectively via face-to-face questionnaire form. Results: The relationship between having knowledge about mammography and the frequency of mammography was examined and it has been statistically shown that patients who have knowledge about mammography have taken mammography more regularly and frequently. The relationship between complaints of admission to the general surgery policlinic and smoking was examined and it was statistically shown that complaints of the smokers were more frequent. Conclusion: Early diagnosis of breast cancer gives a chance to have a healthy life while at the same time enables breast preserving surgery with early diagnosis and increases the quality of life. It is necessary to accelerate the level of patient knowledge and awareness.
\end{abstract}

Keywords: Breast Cancer, Knowledge, Mammography, Questionnaires, Smoking, Survey

\section{Introduction}

Breast cancer is the most common cancer with a rate of $33 \%$ in female [1-3]. It accounts for $20 \%$ of cancer-related deaths and is the second most cause of cancer death in women all over the world $[1,4]$. The incidence of breast cancer varies between countries and regions. The frequency of breast cancer decreases from north to south and from west to east in Europe. However, this difference is steadily declining as the economy grows and fertility becomes more similar to the West [2]. Demographic characteristics (sex, race, age), reproductive history (menarche age, parturition, pregnancy age, breast-feeding history), familial-genetic factors (BRCA 1-2 gene mutation), environmental factors (radiotherapy story, hormone replacement therapy, alcohol consumption, socioeconomic level) have major effect $[1,2]$. The incidence of brest cancer in Turkey is reported as $35 \%$ based on data from the Ministry of Health [1, 4]. As each country must do to reduce or even prevent the risk of breast cancer, we also need to determine the risk groups in Turkey and arrange the frequency of screening programs [1]. Breast cancer becomes more important because of the high frequency, high survival rate when it is diagnosed and treated at an early stage, and easy to diagnose with screening tools [4-6]. Some changes in lifestyle may reduce the breast cancer risk and the risk of death from breast cancer can be reduced with regular mammography screening programs [1]. A life-threatening cancer with a high incidence, increases social awareness and anxiety. For this reason, high risk groups are identified and informed [4]. Due to the religion and traditional structure of Turkey, having children and breast-feeding becomes a part of motherhood. Carbonhydrate predominantly nutrition and very limited alcohol consumption are protective factors against breast cancer in Turkey. However, limited physical activity and insufficient use of screening programs are also considered as increasing risk factors [2]. There are few studies conducted in Turkey for early diagnosis and treatment of breast cancer, and aiming to raise social awareness, and 
yet not enough numbers have been reached. For this reason, the chance of early diagnosis and curative treatment in Turkey falls [6]. We aimed to improve the chance of early diagnosis and curative treatment, to evaluate the level of knowledge about breast diseases and complaints, to increase the awareness and relationship between patients and surgeons, and to put forth the patient's expectations from surgeons because of the importance of breast cancer in Turkey.

\section{Materials and Methods}

100 female patients, who were admitted to general surgery policlinic of our hospital between January 2016 to April 2016 with complaints of breast disease were studied prospectively via face-to-face questionnaire form. Breast Disease Questionnaire Form consisting of 27 questions was used in the study. This study was approved by the IRB of our instution. 100 patients who admitted to general surgery policlinic were selected randomly with no spesific criteria in the selection of the universe and the sample. Inclusion criterias were female gender and admitted to general surgery policlinic with complaints of breast disease. Exclusion criteria was male gender. A total of 100 questionnaire forms were evaluated by Department of Biostatistics with Statistical Package for Social Science (SPSS) program version 22.0. Pearson Chi-square test was used for statistical evaluation and $p$ value $<0.05$ was considered statistically significant.

\section{Results}

A total of 100 patients; 38 patients (38\%) had mass in the breast, 23 patients $(23 \%)$ had nipple discharge, 22 patients $(22 \%)$ had pain, 15 patients $(15 \%)$ had erythema, and 2 patients (2\%) had other complaints. 58 (58\%) patients answered 'No' while 42 patients (42\%) answered 'Yes' to the question of 'Have you ever admitted to the doctor?'. Of the 100 patients who participated for the questionnaire, 83 patients $(83 \%)$ were stated that they performed breast selfexamination but the remaining 17 patients $(17 \%)$ stated that they did not. For the question of 'If you perform breast selfexamination, how often do you perform it?'; 28 patients $(28 \%)$ answered 'monthly', 28 patients $(28 \%)$ answered 'every six months', 18 patients (18\%) answered 'every week', 13 patients $(13 \%)$ answered 'every three months', and 13 patients (13\%) answered 'other'. Atotal of 100 participitans, 49 patients $(49 \%)$ stated that they learned the breast examination from the 'doctor', 21 patients $(21 \%)$ stated that they learned from the 'television', 16 patients $(16 \%)$ stated that they learned from the 'internet', 4 patients (4\%) stated that they learned from the 'newspaper', and 13 patients (13\%) stated that they learned from the 'other' sources. A total of $61(61 \%)$ patients had no 'family history' of breast disease while 39 (39\%) had. For the question of 'What would you do to reduce the risk if you are at high risk group?'; 39 patients (39\%) answered 'relinquish the decision to the doctor', 19 patients (19\%) answered 'risk reduction drug use', 10 patients (10\%) answered 'fall out of breast', 27 patients (27\%) answered 'I will follow up frequently' and 5 patients (5\%) answered 'accept my fate'. For the question of 'Do you have any information about mammography?'; 65 patients (65\%) answered 'Yes' while 35 patients (35\%) answered 'No'. 54 patients $(54 \%)$ were non-smoker while 46 (46\%) were smoker. The relationship between those who have family history of breast disease and breast self-examination was examined and there was no statistically significant relationship with a $\mathrm{p}$ value of 0.426 (Table 1 ).

Table 1. The relationship between family history and breast self-examination in breast diseases.

\begin{tabular}{|c|c|c|c|c|c|c|}
\hline & & & \multicolumn{2}{|c|}{ Breast Self-examination? } & \multirow[b]{2}{*}{ Total } & \multirow[b]{2}{*}{$\mathbf{p}$} \\
\hline & & & No & Yes & & \\
\hline \multirow{4}{*}{ Family History of breast disease } & No & $\mathrm{n}$ & 12 & 49 & 61 & \multirow{6}{*}{0.426} \\
\hline & NO & $\%$ & $19.7 \%$ & $80.3 \%$ & $100,00 \%$ & \\
\hline & Yes & $\mathrm{n}$ & 5 & 34 & & \\
\hline & Tes & $\%$ & $12.8 \%$ & $87.2 \%$ & $100,00 \%$ & \\
\hline \multirow{2}{*}{ Total } & & $\mathrm{n}$ & 17 & 83 & 100 & \\
\hline & & $\%$ & $17,00 \%$ & $83,00 \%$ & $100,00 \%$ & \\
\hline
\end{tabular}

$\mathrm{P}$ value $<0.05$ is statistically significant

The relationship between having knowledge about mammography and the frequency of mammography was examined and it has been statistically shown that patients who have knowledge about mammography have taken mammography more regularly and frequently with a $\mathrm{p}$ value of 0.005 (Table 2).

Table 2. The relationship between knowledge and frequency about mammography.

\begin{tabular}{|c|c|c|c|c|c|c|c|c|c|}
\hline & & & \multicolumn{5}{|c|}{ Frequency of mammography } & \multirow{2}{*}{ Total } & \multirow[b]{2}{*}{$\mathbf{p}$} \\
\hline & & & Clinician's advise & Yearly & Not regularly & Biennially & Never & & \\
\hline \multirow{4}{*}{$\begin{array}{l}\text { Knowledge about } \\
\text { mammography }\end{array}$} & No & $\mathrm{n}$ & 2 & 3 & 11 & 5 & 14 & 35 & \multirow{6}{*}{0.005} \\
\hline & NO & $\%$ & $5.7 \%$ & $8.6 \%$ & $31.4 \%$ & $14.3 \%$ & $40,00 \%$ & $100,00 \%$ & \\
\hline & Yes & $\mathrm{n}$ & 20 & 13 & 14 & 8 & 10 & 65 & \\
\hline & Yes & $\%$ & $30.8 \%$ & $20,00 \%$ & $21.5 \%$ & $12.3 \%$ & $15.4 \%$ & $100,00 \%$ & \\
\hline \multirow{2}{*}{ Total } & & $\mathrm{n}$ & 22 & 16 & 25 & 13 & & 100 & \\
\hline & & $\%$ & $22,00 \%$ & $16,00 \%$ & $25,00 \%$ & $13,00 \%$ & $24,00 \%$ & $100,00 \%$ & \\
\hline
\end{tabular}

$P$ value $<0.05$ is statistically significant 
The relationship between complaints of admission to the general surgery policlinic and smoking was examined and it was statistically shown that complaints of the smokers were more frequent with a p value of 0.037 (Table 3 ).

Table 3. The relationship between complaints of breast diseases and smoking.

\begin{tabular}{|c|c|c|c|c|c|c|}
\hline & & & \multicolumn{2}{|c|}{ Smoking } & \multirow{2}{*}{ Total } & \multirow[b]{2}{*}{$\mathbf{p}$} \\
\hline & & & No & Yes & & \\
\hline \multirow{10}{*}{$\begin{array}{l}\text { Complaints of Admission } \\
\text { to the Policlinic }\end{array}$} & Other & $\mathrm{n}$ & 1 & 1 & 2 & \multirow{12}{*}{0.037} \\
\hline & Uther & $\%$ & $50,00 \%$ & $50,00 \%$ & $100,00 \%$ & \\
\hline & & $\mathrm{n}$ & 16 & 6 & 22 & \\
\hline & Pain & $\%$ & $72.7 \%$ & $27.3 \%$ & $100,00 \%$ & \\
\hline & Macs & $\mathrm{n}$ & 21 & 17 & 38 & \\
\hline & Mass & $\%$ & $55.3 \%$ & $44.7 \%$ & $100,00 \%$ & \\
\hline & Enuthome & $\mathrm{n}$ & 3 & 12 & 15 & \\
\hline & Erytnema & $\%$ & $20,00 \%$ & $80,00 \%$ & $100,00 \%$ & \\
\hline & & $\mathrm{n}$ & 13 & 10 & & \\
\hline & Nipple Discharge & $\%$ & $56.5 \%$ & $43.5 \%$ & $100,00 \%$ & \\
\hline \multirow{2}{*}{ Total } & & $\mathrm{n}$ & 54 & 46 & 100 & \\
\hline & & $\%$ & $54,00 \%$ & $46,00 \%$ & $100,00 \%$ & \\
\hline
\end{tabular}

$P$ value $<0.05$ is statistically significant

Limitations: There is a small group of patients in this study and there is no specific criteria for exclusion.

\section{Discussion}

Early diagnosis of breast cancer gives a chance to have a healthy life while at the same time enables breast preserving surgery with early diagnosis and increases the quality of life. In western countries where awareness is increased and screening programs are used effectively, the rate of asymptomatic breast cancer diagnosis and associated breast preserving surgery rates are as high as $75 \%$ [3]. The Department of General Surgery is responsible for the 'surgical treatment' of breast cancer in Turkey. Other departments including Pathology, Radiology, Medical Oncology, Radiation Oncology, Nuclear Medicine and Physical Therapy and Rehabilitation are responsible for diagnosis and other treatment strategies [3, 5]. For optimal treatment of breast cancer, the department of Radiology, General Surgery and Pathology are necessary [3]. It is observed that the rate of locally advanced breast cancer is approximately $50 \%$ in the eastern part of Turkey and this ratio is between $15 \%$ and $30 \%$ in the western part of country. This data shows us that the early diagnosis is directly affected by the level of education, awareness, and increasing quality of adaptation between clinician and patient. For this reason, it is necessary to accelerate the level of patient knowledge and awareness. In a study reported that women heard breast self-examination from sources such as written and visual media. However, the rates of breast selfexamination were very low. It was also observed that nonliterate people never examined themselves. Women need regular breast self-examinations every month so that they can detect changes in their breast. Approximately $90 \%$ of breast cancers are diagnosed by referrals to the doctor as a result of self-examination by themselves [7, 8]. As a result of systematic and regular screening, the satisfactory results can be obtained [9]. Richards et al. reported that delayed diagnosis of breast cancer for three months or longer has been shown to worsen the stage of breast cancer and shorten the survival of patients [10]. It has been demonstrated that elderly age is an important parameter for late admission and delayed diagnosis in the study of Ramirez et al [11]. Burgess et al. showed that the negative attitude towards the clinician and illness was the most important factor leading to delayed admission and diagnosis [12]. Hedef et al. demonstrated that most of the patients did not want to examine, did not want laboratuary-screening studies, and they had made a mistake in breast self-examination too [6]. A study in Malaysia reported that the rate of regular breast self-examinations was $1.3 \%$ and that this rate was $2.9 \%$ in families with breast cancer stories [13]. 'Patient questionnaire' should be used to determine patient satisfaction in social surveys. In these forms, questions should be asked about issues that need to be corrected other than demographic information and which are required to raise awareness [14]. In a study in Turkey, the time elapsed between detection of the symptom and admission to the general surgery policlinic was found to be 10 days on average. The mean time between surgery and adjuvant treatment was 31 days. These periods were found longer in Turkey [15].

\section{Conclusion}

In order to increase the effectiveness of breast cancer diagnosis and treatment programs all over the world, a large number of studies aiming at increasing the knowledge level and awareness of patients about the disease should be planned. We also aim to increase breast disease and breast cancer management to a level above that of European countries by increasing face-to-face surveys and patientclinician compliance and confidence. Overall mortality related to breast cancer can only reduce by leading the regular screening programs for breast diseases and increase the awareness and relationship between patients and clinicians, and to put forth the patient's expectations from clinicians because of the importance of breast cancer. 


\section{Conflict of Interest Source of Funding Statement}

The manuscript, as submitted or its essence in another version, is not under consideration for publication elsewhere, and will not be published while under consideration European Journal of Preventive Medicine. The author have no commercial associations or sources of support that might pose a conflicy of interest.

\section{Acknowledgements}

Special thanks to Alperen Ibrahim Sayar and Erdogan Anık for helping to questionnaire survey.

\section{References}

[1] Koçak S, Çelik L, Özbaş S, Dizbay Sak S, Tükün A, Yalçın B. Risk Factors in Breast Cancer, Risk Assessment and Prevention: 2010 Istanbul Consensus Meeting Report. J Breast Health 2011; 7 (2): 47-67.

[2] Aslan FE, Gürkan A. The Risk of Breast Cancer At the Women. J Breast Health 2007; 3 (2): 63-68.

[3] Özmen V. Meme Hastalıklarının Cerrahi Tedavi Kalitesi Nasıl Yükseltilebilir?. J Breast health 2009; 5 (3): 119-121.

[4] Dinçel O, Başak F, Pektaş B, Kınacı E. Breast Cancer Risk Assessment and Level of Knowledge in Women with Low Levels of Education. J Kartal TR 2014; 25 (3): 181-186.

[5] Güler SA, Güllüoğlu BM. Quality Assurance in Breast Health Care and Requirement for Accreditation in Specialized Units. J Breast Health 2014; 10: 129-133.

[6] Özgün H, Soyder A, Tunçyürek P. Factors Effecting the
Delayed Presentation in Breast Cancer. J Breast Health 2009; 5 (2): 87-91.

[7] Alpteker H, Avc1 A. Determine the Knowledge of the Women About Breast Cancer and Their Practice About Breast Self Examination. J Breast Health 2010; 6 (2): 74-79.

[8] Stillman MJ. Woman's Health Beliefs About Breast Cancer and Breast Self-examination. Nurs Res 1977; 26 (2): 121-127.

[9] Freund KM, Battaglia TA, Calhoun E, Dudley DJ, Fiscella K, Paskett E, et al. Nation Cancer Institute Patient Navigation Research Program: Methods, Protocol, and Measures. Cancer 2008; 113 (12): 3391-3399.

[10] Richards MA, Westcombe AM, Love SB, Littlejohns P, Ramirez AJ. Influence of Delay on Survival in Patients with Breast Cancer: A Systematic Review. Lancet 1999; 353: 11191126.

[11] Ramirez AJ, Westcombe AM, Burgess CC, Sutton S, Littlejohns P, Richards MA. Factors Predicting Delayed Presentation of Symptomatic Breast Cancer: A Systematic Review. Lancet 1999; 353: 1127-1131.

[12] Burgess C, Hunter MS, Ramirez AJ. A Qualitative Study of Delay Among Women Reporting Symptoms of Breast Cancer. Br J Gen Pract 2001; 51: 967-971.

[13] Hisham AN, Yip CH. Overview of Breast Cancer in Malaysian Women: A Problem with Late Diagnosis. Asian J Surg 2004; 27: 130-133.

[14] Düşünceli F, Manukyan MN, Albas Ö, Eser S, Turan G, Geniş $\mathrm{N}$, et al. How Satisfactory are Health Services in a Multidisciplinary Breast Center fort he patient? J Breast Health 2005; 12: 31-37.

[15] Saip P, Keskin S, Özkan M, Kaplan MA, Aydoğan F, Demirağ GG, et al. The Access Time of Breast Cancer Patients to Diagnosis and Treatment Methods in Turkey; Multicenter Observational Study. J Breast Health 2011; 2: 109-117. 